\title{
Pulmonary hypertension at high altitude
}

\author{
Robert Naeije
}

Affiliation: Erasme University Hospital, Brussels, Belgium.

Correspondence: Robert Naeije, Dept of Physiology, Erasme Campus CP 604, 808 Lennik Road, B-1070 Brussels, Belgium. E-mail: rnaeijeđuulb.ac.be

@ERSpublications

Pulmonary hypertension at high altitude is uncommon http://bit.ly/2JxD2Q3

Cite this article as: Naeije R. Pulmonary hypertension at high altitude. Eur Respir J 2019; 53: 1900985 [https://doi.org/10.1183/13993003.00985-2019].

In the present issue of the European Respiratory Journal, SoRIA et al. [1] report on a meta-analysis of echocardiographic estimates of systolic pulmonary artery pressure (sPAP) in 287 patients (nine studies) with chronic mountain sickness (CMS) at rest and in 142 of them (five studies) also at exercise. The results are surprising. Mean pulmonary artery pressure (mPAP), here recalculated as $0.6 \times \mathrm{sPAP}+2 \mathrm{mmHg}$ [2], was on average $18 \mathrm{mmHg}(95 \% \mathrm{CI} 16-20 \mathrm{mmHg})$ at rest and $31 \mathrm{mmHg}(95 \% \mathrm{CI} 29-33 \mathrm{mmHg})$ during exercise, suggesting no pulmonary hypertension $(\mathrm{PH})$ at rest but mild $\mathrm{PH}$ during exercise. The same authors had previously reported on a similar meta-analysis in a larger number of 834 healthy high altitude dwellers at rest, showing a mPAP of $18 \mathrm{mmHg}$ and a maximum of $24 \mathrm{mmHg}$, compared to $13 \mathrm{mmHg}$ and a maximum of $20 \mathrm{mmHg}$, respectively, in sea level controls [3]. On the basis of these data altogether, SoRIA et al. [1] conclude that high altitude dwellers with or without CMS have no PH at rest, but CMS patients commonly present with exercise-induced $\mathrm{PH}$, which may be of symptomatic and of prognostic relevance. This is provocative, as altitude is listed as "hypoxia without lung disease" in the updated classification of $\mathrm{PH}$, and experts remain unconvinced about the notion of exercise-induced PH [4].

The upper limit of normal of resting mPAP is $20 \mathrm{mmHg}$ [5]. PH used to be defined by mPAP $\geqslant 25 \mathrm{mmHg}$, allowing for a $5 \mathrm{mmHg}$ safety margin to decrease the likelihood of false-positives [6-8]. This cut-off value was most recently brought down to $20 \mathrm{mmHg}$ based on the evidence of prognostic and functional relevance of all-cause higher than normal values [4]. In the meantime, altitude experts still define $\mathrm{PH}$ by $\mathrm{mPAP} \geqslant 30 \mathrm{mmHg}$ (sPAP $\geqslant 50 \mathrm{mmHg}$ ) [9]. Thus, altitude dwellers have $\mathrm{PH}$ or not, depending on definitions. With the "traditional" definition of a mPAP $\geqslant 25 \mathrm{mmHg}$, less than $1 \%$ of high altitude dwellers would suffer from $\mathrm{PH}$. With the definition of $\mathrm{mPAP} \geqslant 30 \mathrm{mmHg}, \mathrm{PH}$ at high altitudes should be very rare. A consensus evidence-based revised definition of $\mathrm{PH}$ at high altitudes is obviously needed. As it is, one does not know whether $\mathrm{PH}$ is a public health problem or a rarity for the estimated 120 million people living at altitudes higher than $2500 \mathrm{~m}$.

Exercise increases mPAP because of associated increases in cardiac output (CO) and pulmonary artery wedge pressure (PAWP). The upper limits of normal for mPAP-CO and PAWP-CO relationships have been proposed to be $3 \mathrm{mmHg} \cdot \mathrm{min} \cdot \mathrm{L}^{-1}$ and $2 \mathrm{mmHg} \cdot \mathrm{min} \cdot \mathrm{L}^{-1}$, respectively $[10,11]$. These cut-off values were recently confirmed $[12,13]$. Thus, total pulmonary vascular resistance (PVR), or mPAP/CO should not normally exceed $3 \mathrm{mmHg} \cdot \mathrm{min} \cdot \mathrm{L}^{-1}$ during exercise, and higher values define "exercise $\mathrm{PH}$ " [14]. Exercise $\mathrm{PH}$ would also be defined by PVR or (mPAP-PAWP)/CO exceeding $2 \mathrm{mmHg} \cdot \mathrm{min} \cdot \mathrm{L}^{-1}$ [11]. SORIA et al. [1] estimated exercise PVR of $2.7 \pm 0.3 \mathrm{mmHg} \cdot \mathrm{min} \cdot \mathrm{L}^{-1}$ in CMS patients and $2.2 \pm$ $0.6 \mathrm{mmHg} \cdot \mathrm{min} \cdot \mathrm{L}^{-1}$ in healthy highlander controls, suggesting that mild exercise $\mathrm{PH}$ might indeed be common at high altitudes. However, a correction for haematocrit using a recently introduced diagram [15] 
smoothed out the difference between CMS patients and controls. The authors did not address the issue of the contribution of increased haematocrit to high altitude exercise $\mathrm{PH}$.

Altitude exposure is associated with adaptive increase in red blood cell mass. In CMS, this response is excessive, resulting in polycythaemia (i.e. greater than mean+2SD of healthy altitude controls), severe hypoxaemia and neurological symptoms, such as headache, somnolence, fatigue and depression [9]. CMS occurs in native or long-term residents above $2500 \mathrm{~m}$, and is reversible at lower altitudes. Diagnostic cut-off values are haemoglobin $\geqslant 21 \mathrm{~g} \cdot \mathrm{dL}^{-1}$ in men, and $\geqslant 19 \mathrm{~g} \cdot \mathrm{dL}^{-1}$ in women. The underlying mechanism accounting for CMS is a loss of ventilatory adaptation to altitude [16]. Increased haemoglobin levels in these patients contribute to hypoventilation by allowing for more carbon dioxide output at any given level of carbon dioxide tension [17].

Increased red blood cell mass during high altitude exposure increases blood viscosity. The relationship between PVR and blood viscosity is linear. The relationship between haematocrit and blood viscosity is curvilinear. Estimates of PVR for the diagnosis of pulmonary vascular disease at high altitudes can be corrected for haematocrit, which is easier to measure than viscosity. Correction equations are complex, and thus best replaced by a diagram plotting PVR as a function of haematocrit [15]. It is intriguing that haematocrit-corrected PVR was found to be similar in high altitude Andean Quechua, Himalayan Sherpa or high altitude sojourners [18]. Pioneer studies in the 1950s had already concluded that hypoxic PH on the Andean altiplano was mainly explained by an increased haematocrit [19].

One could wonder if exercise $\mathrm{PH}$, at the level seen at high altitudes, could impair the coupling of right ventricular (RV) function to the pulmonary circulation. This does not seem to happen. Echocardiographic studies of the RV in CMS patients at rest and at exercise have shown an adequate increase in RV contractility to preserve RV-pulmonary artery (PA) coupling [20]. Combined cardiopulmonary exercise testing and echocardiographic examinations have shown that maximum oxygen uptake is preserved in spite of steep mPAP-CO relationships in CMS patients, suggesting no RV limitation to aerobic exercise capacity [21]. Steep mPAP-CO relationships in exercising CMS patients have been shown to be associated with increased lung water, as assessed by lung ultrasound measurements [22], but the clinical significance of this observation is uncertain.

All this is not to say that severe PH never occurs at high altitudes. It has been reported by field invasive studies, though in small numbers and probably fraught with referral bias [23]. It has been occasionally confused with idiopathic pulmonary arterial hypertension triggered in children by chronic hypoxic exposure [24]. Severe PH has been reported as a cause of high altitude pulmonary oedema [25] or high altitude-induced right heart failure [26] in altitude sojourners with uncommonly brisk hypoxic pulmonary vasoconstriction. Right heart failure syndromes have been reported as "brisket disease" in cattle [27] or as "subacute mountain sickness" in children [28] or adults [29] during prolonged stays at high altitudes. Brisket is a butchery term, and CMS has per definition no heart failure component or any preceding acute or sub-acute stages. Therefore, these terminologies are therefore better replaced by the more easily understood "high altitude-induced right heart failure".

The study by Soria et al. [1] could be criticised for relying exclusively on Doppler echocardiography of the pulmonary circulation. However, as underscored by the authors, sPAP calculated from the maximum velocity of tricuspid regurgitation compared to its invasive measurement has been shown to be accurate (no bias on Bland and Altman analysis) but with limited precision (wide limits of agreement on Bland and Altman analysis) at rest [30] and at exercise [31]. Accurate methods with limited precision are adequate for population studies, but less so for individual decision-making [30]. The accuracy of Doppler echocardiography for estimates of $\mathrm{CO}$ and PAWP at rest has been shown to be acceptable as well [30], but may require further validation in exercise [32]. In general, exercise stress echocardiography is nowadays a sufficiently validated approach for the detection and diagnosis of a variety of cardiovascular conditions, including PH and RV-PA uncoupling [32].

SoRIA et al. [1] are to be commended for setting the stage for a better understanding of purely hypoxic $\mathrm{PH}$ and its place in current $\mathrm{PH}$ classifications. Their studies are enlightening, but also show how much remains to be done. Altitude experts should be invited to participate in future $\mathrm{PH}$ expert meetings to agree on revised definitions and terminology. Noninvasive approaches should be further validated and extensively implemented. To what extent $\mathrm{PH}$ and right heart failure are public health problems or rarities in high altitude communities needs to be addressed with updated methodology and large scale population studies.

Conflict of interest: None declared.

References

1 Soria R, Egger M, Scherrer U, et al. Pulmonary artery pressure at rest and during exercise in chronic mountain sickness: a meta-analysis. Eur Respir J 2019; 53: 1802040. 
2 Chemla D, Castelain V, Humbert $\mathrm{M}$, et al. New formula for predicting mean pulmonary artery pressure using systolic pulmonary artery pressure. Chest 2004; 126: 1313-1317.

3 Soria R, Egger M, Scherrer U, et al. Pulmonary artery pressure and arterial oxygen saturation in people living at high or low altitude: systematic review and meta-analysis. J Appl Physiol 2016; 121: 1151-1159.

4 Simonneau G, Montani D, Celermajer DS, et al. Haemodynamic definitions and updated clinical classification of pulmonary hypertension. Eur Respir J 2019; 53: 1801913.

5 Kovacs G, Berghold A, Scheid S, et al. Pulmonary artery pressure during rest and exercise in healthy subjects: a systematic review. Eur Respir J 2009; 34: 888-894.

6 Hatano S, Strasser T. Primary Pulmonary Hypertension: Report on a WHO Meeting, Geneva, 15-17 October 1973. Geneva, World Health Organization, 1975.

7 Rich S, Dantzker DR, Ayres SM, et al. Primary pulmonary hypertension: a national prospective study. Ann Intern Med 1987; 107: 216-223.

8 Hoeper MM, Bogaard HJ, Condliffe R, et al. Definitions and diagnosis of pulmonary hypertension. J Am Coll Cardiol 2013; 62: Suppl. 25, D45-D50.

9 Leon-Velarde F, Maggiorini M, Reeves JT, et al. Consensus statement on chronic and subacute high altitude diseases. High Alt Med Biol 2005; 6: 147-157.

10 Naeije R, Vanderpool R, Dhakal BP, et al. Exercise-induced pulmonary hypertension: physiological basis and methodological concerns. Am J Respir Crit Care Med 2013; 187: 576-583.

11 Naeije R, Saggar R, Badesch D, et al. Exercise-induced pulmonary hypertension: translating pathophysiological concepts into clinical practice. Chest 2018; 154: 10-15.

12 Herve P, Lau EM, Sitbon O, et al. Criteria for diagnosis of exercise pulmonary hypertension. Eur Respir J 2015; 46 : $728-737$.

13 Eisman AS, Shah RV, Dhakal BP, et al. Pulmonary capillary wedge pressure patterns during exercise predict exercise capacity and incident heart failure. Circ Heart Fail 2018; 11: e004750.

14 Kovacs G, Herve P, Barbera JA, et al. An official European Respiratory Society statement: pulmonary haemodynamics during exercise. Eur Respir J 2018; 50: 1700578.

15 Vanderpool RR, Naeije R. Hematocrit-corrected pulmonary vascular resistance. Am J Respir Crit Care Med 2018; 198: 305-309.

16 Leon-Velarde F, Richalet JP. Respiratory control in residents at high altitude: physiology and pathophysiology. High Alt Med Biol 2007; 7: 125-137.

17 Naeije R, Vanderpool R. Pulmonary hypertension and chronic mountain sickness. High Alt Med Biol 2013; 14 $117-125$.

18 Faoro V, Huez S, Vanderpool RR, et al. Pulmonary circulation and gas exchange at exercise in sherpas at high altitude. J Appl Physiol 2014; 116: 919-926.

19 Canepa AA R, Hurtado A, Velasquez T, et al. Pulmonary circulation at sea level and at high altitude. J Appl Physiol 1956; 9: 328-336.

20 Pratali L, Allemann Y, Rimoldi SF, et al. RV contractility and exercise-induced pulmonary hypertension in chronic mountain sickness: a stress echocardiographic and tissue Doppler imaging study. JACC Cardiovasc Imaging 2013; 6: 1287-1297.

21 Groepenhoff $\mathrm{H}$, Overbeek MJ, Mulè $\mathrm{M}$, et al. Exercise pathophysiology in patients with chronic mountain sickness. Chest 2012; 142: 877-884.

22 Pratali L, Rimaldi SF, Rexhaj E, et al. Exercise induces rapid interstitial lung water accumulation in patients with chronic mountain sickness. Chest 2012; 141: 953-958.

23 Penaloza D, Arias-Stella J. The heart and pulmonary circulation at high altitudes. Healthy highlanders and chronic mountain sickness. Circulation 2007; 115: 1132-1146.

24 Khoury GH, Hawes CR. Primary pulmonary hypertension in children living at high altitude. J Pediatr 1963; 62: 177-185.

25 Maggiorini M, Mélot C, Pierre S, et al. High altitude pulmonary edema is initially caused by an increased capillary pressure. Circulation 2001; 103: 2078-2083.

26 Huez S, Faoro V, Vachiery JL, et al. Images in cardiovascular medicine. High-altitude-induced right-heart failure. Circulation 2007; 115: e308-e309.

27 Hecht HH, Kuida H, Lange RL, et al. Brisket disease. Am J Med 1962; 32: 171-183.

28 Sui GJ, Liu YH, Cheng XS. Subacute infantile mountain sickness. J Pathol 1988; 155: 161-170.

29 Anand IS, Malhotra R, Chandershekhar Y, et al. Adult subacute mountain sickness: a syndrome of congestive heart failure in man at very high altitude. Lancet 1990; 335: 561-565.

30 D'Alto $\mathrm{M}$, Romeo E, Argiento $\mathrm{P}$, et al. Accuracy and precision of echocardiography versus right heart catheterization for the assessment of pulmonary hypertension. Int J Cardiol 2013; 168: 4058-4062.

31 van Riel AC, Opotowsky AR, Santos M, et al. Accuracy of echocardiography to estimate pulmonary artery pressures with exercise: a simultaneous invasive-noninvasive comparison. Circ Cardiovasc Imaging 2017; 10: e005711.

32 Rudski LG, Gargani L, Armstrong WF, et al. Stressing the cardiopulmonary vascular system: the role of echocardiography. J Am Soc Echocardiogr 2018; 31: 527-550. 